\title{
Collapsing glomerulopathy in Portugal: a review of the histological and clinical findings in HIV and non-HIV patients
}

\author{
Ana Carina Ferreira ${ }^{1}$, Dulce Carvalho ${ }^{1}$, Fernanda Carvalho ${ }^{1,2}$, Maria João Galvão ${ }^{2}$ and Fernando Nolasco ${ }^{1}$ \\ ${ }^{1}$ Department of Nephrology and ${ }^{2}$ Renal Pathology Laboratory, Hospital de Curry Cabral, Lisbon, Portugal \\ Correspondence and offprint requests to: Ana Carina Ferreira; E-mail: karinadacostafer@hotmail.com
}

\begin{abstract}
Background. Collapsing glomerulopathy $(\mathrm{CG})$ is a glomerulonephritis seen in association with human immunodeficiency virus (HIV) infection, known as HIV-associated nephropathy (HIVAN), and less frequently observed in non-HIV-infected patients.

Method. The aim of this study was to review the histological and clinical findings of all CG diagnosed since 1981 in our laboratory.

Result. Since 1981, 18 kidney biopsies with collapsing features were diagnosed among 6130 biopsies performed: $72.2 \%(n=13)$ males, mean age $33.8 \pm 9.7$ years, $61.1 \%$ $(n=11)$ of black ethnic origin. HIV infection was present in 10 patients. Mean serum creatinine (Scr) was $4.7 \pm$ $2.5 \mathrm{mg} / \mathrm{dL}$, and mean proteinuria was $6.1 \pm 5 \mathrm{~g} / 24 \mathrm{~h}$. Both HIVAN and non-HIVAN patients were similar in terms of age, gender and dialysis requirement.

In the HIVAN population, African origin was predominant and more frequent than in the non-HIVAN population, Scr was higher and proteinuria was less severe. Interstitial infiltrate, interstitial fibrosis and tubular atrophy were severe, and the presence of microcystic dilatation of renal tubules was more common. Immunofluorescence was positive in six patients. In the non-HIVAN population, this histological lesion was related to an infectious illness in 6/8 patients and to the use of illegal oral drugs in one patient. Interstitial infiltrate, interstitial fibrosis and tubular atrophy presented as moderate to severe, and tubular atrophy correlated with dialysis requirement. Mesangial proliferation was present in 3/8 patients, with $\mathrm{C} 3$ and IgA deposits.

Conclusion. CG is a rare podocytopathy. In this study, the association between infection and CG is evident, and we may suggest that infections could, in a direct or indirect manner, be a trigger of podocyte injury.
\end{abstract}

Keywords: collapsing glomerulopathy; HIVAN; infections; renal biopsy

\section{Introduction}

Collapsing glomerulopathy (CG) is, according to Columbia classification, an aggressive morphologic variant of focal segmental glomerulosclerosis (FSGS) [1,2], characterized by severe proteinuria, rapidly progressive renal failure and poor response to therapy $[2,3]$. The pathological features of CG are segmental or global glomerular capillary loop collapse with marked proliferation and hypertrophy of overlying podocytes associated to noticeable tubulointerstitial disease [1].

This is a newly debated disease, seen usually in association with human immunodeficiency virus (HIV) infection, known as HIV-associated nephropathy (HIVAN), and relatively rare in non-HIV-infected patients [4,5]. Although in this group of patients, most cases are idiopathic [1], there have been cases associated with systemic or febrile illness $[3,6-9]$ or drugs exposure [3,10-12]. Whether CG is associated with HIV or with any other aetiology, the pathogenesis probably involves visceral epithelial cell injury, which causes marked dysregulation of the normal podocyte phenotype and aberrant proliferation of tubular epithelium, leading to microcystic dilatation of renal tubules accompanied by cellular infiltrate [3].

The aim of this study was to review the histological characteristics and clinical findings on all native renal biopsies with collapsing features received by our pathology laboratory since 1981.

\section{Materials and methods}

\section{Study design}

This was a retrospective review of all biopsies with collapsing features received by the Renal Pathology Laboratory of the Curry Cabral Hospital, from 1981 to March 2010. Our laboratory receives biopsies from our hospital, from the hospitals in the south of Portugal and from the Atlantic Portuguese islands.

The biopsies were re-examined by two independent investigators. Slides examined by light microscopy contained at least six glomeruli per section, and at least one glomerulus with segmental or global capillary collapse with wrinkling of the basement membrane and crowding of the epithelial cells was required for the diagnosis of CG. The degree of active interstitial infiltrate, interstitial fibrosis and tubular atrophy was estimated as a percentage of the cortical involved, and was considered mild if $<30 \%$, moderate if between 30 and $60 \%$ and severe if $>60 \%$. The presence of dilatation or microcysts of renal tubules, acute tubular necrosis and the vessel status were noted. Immunofluorescence microscopy of each biopsy was reviewed. Electron microscopy was examined when available.

Clinical and laboratory data from these patients at the time of biopsy were obtained. We recorded age, gender, race, presence of viral infections, namely HIV, hepatitis B virus (HBV), hepatitis C virus (HCV) and cyto- 
megalovirus infection (CMV), presence of an acute febrile illness, autoimmune or malignancy disease, drug abuse, regular medication, dialysis requirement, serum creatinine (Scr) values, 24-h proteinuria and presence of haematuria, serological study for autoimmune disease (antinuclear antibodies, C3 and C4 levels), serum and urinary electrophorectic studies. Type of treatment and time of follow-up were registered.

\section{Statistical analysis}

Data are presented as mean $\pm \mathrm{SD}$ values for normally distributed variables or as frequencies for categorical variables. Independent variables were compared using the Mann-Whitney and the chi-square tests. All tests were performed using the SPSS system 18.0, and a $\mathrm{P}<0.05$ was considered statistically significant.

\section{Results}

Since 1981, our laboratory received 6130 native renal biopsies. In 413, we found histological features of FSGS and in only 18 of these, features of collapsing glomerulosclerosis. Prior to 1994 there were 154 cases of FSGS, but no CG. Our first case was in 1994, in a non-HIV patient. Since 1994 and up to 1998 , there have been no known cases of CG in our hospital. From 1998 to 2010, sporadic cases of CG have been found, while the number of FSGS remained about the same. HIVAN cases were mainly found before 2001 (Figure 1).

The baseline clinical characteristics of patients are summarized in Table 1. A total of 18 patients were identified, with a mean age of $33.7 \pm 9.8$ years. There was a predominance of young males $(72.2 \%, n=13)$, and $61.1 \%$ of the population were of African origin $(n=11)$. HIV1 infection was present in 10 patients. Mean Scr was $4.7 \pm 2.5 \mathrm{mg} / \mathrm{dL}$, and mean proteinuria was $6.1 \pm 5 \mathrm{~g} / 24 \mathrm{~h}$. Dialysis was required in $44.4 \%(n=8 / 15)$ of patients.

Renal biopsy was performed due to rapidly progressive renal insufficiency in nine patients, nephrotic syndrome in seven patients and non-nephrotic proteinuria in two patients, both HIV infected.

We analysed the data from HIV- and non-HIV-infected patients separately (Table 2). In regard to clinical charac-

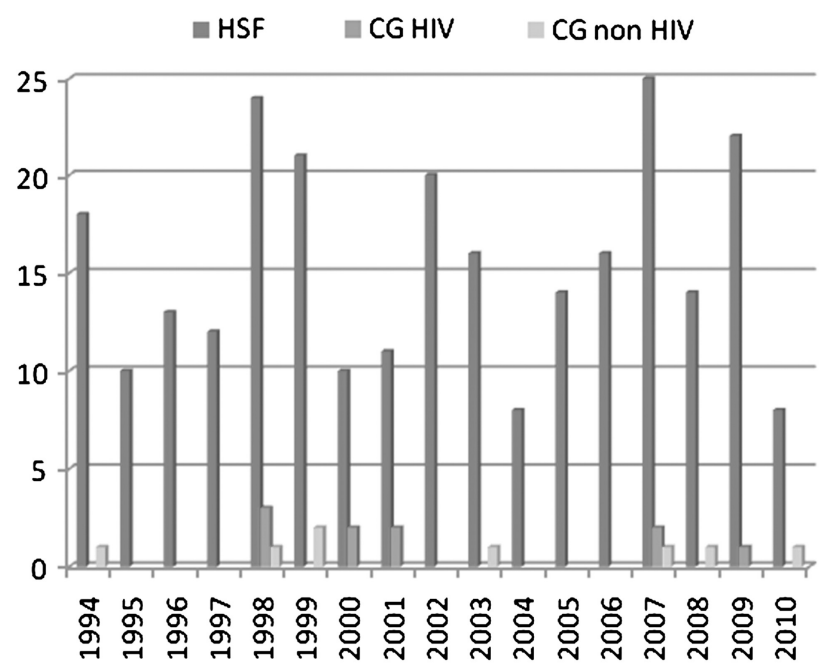

Fig. 1. Distribution of collapsing glomerulopathy in the last 18 years.
Table 1. Clinical characteristics of the population

\begin{tabular}{ll}
\hline Variable & Patients $(n=18)$ \\
\hline Age (year) & $33.7 \pm 9.8$ \\
Gender & \\
$\quad$ Male & $72.2 \%(13)$ \\
Female & $27.8 \%(5)$ \\
Caucasian race $(\%)$ & $38.9 \%(7)$ \\
Black race $(\%)$ & $61.1 \%(11)$ \\
Human immunodeficiency virus infection & $55.6 \%(10)$ \\
Hepatitis B virus infection $(\%)$ & $16.7 \%(3)$ \\
Hepatitis C virus infection $(\%)$ & $11.1 \%(2)$ \\
Renal replacement therapy $(\%)$ & $44.4 \%(8 / 15)$ \\
Serum creatinine (mg/dL) & $4.7 \pm 2.5$ \\
Proteinuria (g/24 h) & $6.1 \pm 5$ \\
Haematuria $(\%)$ & $50 \%(9)$ \\
\hline
\end{tabular}

teristics, no differences were found in terms of gender and dialysis requirement: in both groups, the majority of patients were male and acute dialysis was required in $\sim 50 \%$. Black race was predominant in HIV patients, as compared to Caucasian race in non-HIV patients, Scr was higher and proteinuria was lower. Histological findings revealed a comparable degree of glomeruli injury, with a similar number of collapsed glomeruli and comparable extent of interstitial fibrosis, but tubular atrophy and microcystic dilatation were more evident in HIV patients. Electron microscopy (Figure 2) was similar in both groups, although in HIV-infected patients tubulovesicular bodies were observed in endothelial cell cytoplasm. Outcome was available in nine patients (Table 3), five HIV-infected and four non-HIV-infected patients.

In the HIV population $(n=10)$, black race was predominant $(80 \%)$. In this group, two patients had HCV co-infection and a previous medical history of intravenous drug abuse, and one patient had Kaposi sarcoma (with HHV-8) and miliary tuberculosis. All 10 had AIDS criteria, whereas highly active antiretroviral therapy (HAART) was only used in two patients. CD4 count was low (mean level: $35 \pm 9$ cells $/ \mathrm{mm}^{3}$ ), and HIV RNA levels were high (mean level: 530,902 \pm 2508 copies). There was a trend for higher Scr and lower level of proteinuria compared with non-HIV patients, and histological findings revealed a mean collapsed glomeruli of $3.5 \pm 3.2$ (Figure 3), higher degree of tubular atrophy and microcystic formation. Overall, interstitial infiltrate, interstitial fibrosis and tubular atrophy were considered severe: in four samples all features presented as severe, in one sample interstitial infiltrate and interstitial fibrosis were severe and tubular atrophy was moderate, in four samples interstitial infiltrate was moderate and interstitial fibrosis and tubular atrophy were severe, and in one sample all features were moderate. The presence of microcystic dilatation of renal tubules (Figure 4) was identified in $70 \%$, in comparison to $25 \%$ in non-HIV patients. Immunofluorescence was positive in six patients: two had staining for $\mathrm{C} 3$, one for $\mathrm{C} 3$ and $\mathrm{C} 1 \mathrm{q}$, two for $\mathrm{C} 3$ and $\mathrm{IgM}$ and one for IgM. No staining for IgA was found.

Outcome was available for five patients $(50 \%)$ : two were on dialysis at the time of diagnosis, and remained on dialysis in spite of initiating HAART and died afterwards, two had a favourable response to HAART, with reduced level 
Table 2. Clinical characteristics according to the presence/absence of HIV infection

\begin{tabular}{|c|c|c|}
\hline Variable & HIV-infected patients $(n=10)$ & Non-HIV-infected patients $(n=8)$ \\
\hline Age (year) & $36.7 \pm 9.9$ & $30 \pm 8.9$ \\
\hline Gender (\%) & & \\
\hline Male & $80 \%(8)$ & $62.5 \%(5)$ \\
\hline Female & $20 \%(2)$ & $37.5 \%(3)$ \\
\hline Black race $(\%)$ & $80 \%(8)$ & $37.5 \%(3)$ \\
\hline Hepatitis B virus infection (\%) & $0 \%$ & $25 \%(3)$ \\
\hline Hepatitis $\mathrm{C}$ virus infection (\%) & $20 \%(2)$ & $0 \%$ \\
\hline Renal replacement therapy (\%) & $55.6 \%(5 / 9)$ & $50 \%(3 / 6)$ \\
\hline Serum creatinine $(\mathrm{mg} / \mathrm{dL})$ & $5 \pm 2.3$ & $4.2 \pm 2.7$ \\
\hline Proteinuria $(\mathrm{g} / \mathrm{L})$ & $5 \pm 5.5$ & $7.9 \pm 3.9$ \\
\hline Haematuria $(\%)$ & $50 \%(5)$ & $50 \%(4)$ \\
\hline Mean glomeruli number & $7.8 \pm 3.8$ & $9.7 \pm 4.1$ \\
\hline Mean collapsed glomeruli $(n)$ & $3.5 \pm 3.2$ & $3.8 \pm 2.9$ \\
\hline Mesangial proliferation with $\mathrm{C} 3$ and IgA deposits (\%) & $0 \%$ & $37.5 \%(3)$ \\
\hline \multicolumn{3}{|l|}{ Interstitial infiltrate $(\%)$} \\
\hline Severe & $50 \%(4)$ & $37.5 \%(3)$ \\
\hline \multicolumn{3}{|l|}{ Interstitial fibrosis $(\%)$} \\
\hline Moderate & $10 \%(1)$ & $50 \%(4)$ \\
\hline Severe & $90 \%(9)$ & $50 \%(4)$ \\
\hline \multicolumn{3}{|l|}{ Tubular atrophy (\%) } \\
\hline Moderate & $10 \%(1)$ & $50 \%(4)$ \\
\hline Severe & $90 \%(9)$ & $50 \%(4)$ \\
\hline Microcystic dilatation of tubules & $70 \%(7)$ & $25 \%(2)$ \\
\hline
\end{tabular}

of proteinuria and Scr, and one started HAART but, after 8 months, died due to complications of miliary tuberculosis.

In the non-HIV group $(n=8)$, the patients were slightly younger $(36.7 \pm 9.9$ vs $30 \pm 8.9)$ and Caucasian race was predominant $(62.5 \%)$. In $6 / 8$ patients, there was a concomitant infection: five had an acute febrile illness (two had active pulmonary tuberculosis, one had acute HBV infection, one had acute CMV and Ascaris lombricoides infection and one had community pneumonia with non-identified agent); one patient had chronic HBV infection. One patient consumed illegal oral drugs, namely amphetamines and cocaine. No associated disease was identified in one young female. All patients had negative serology for HCV and for autoimmune diseases, and all had a urinary and serum electrophoresis that excluded monoclonal gammopathy. No neoplasm was identified by clinical examination. No regular medication was noted. These patients had higher pro-

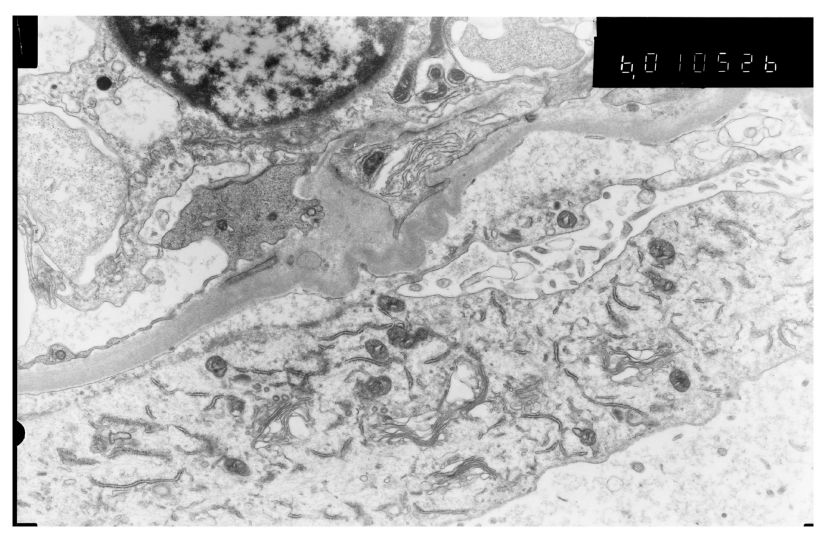

Fig. 2. Wrinkling of basement membrane. Hypertrophy of podocyte with pedicel effacement $(\mathrm{EM} \times 30,000)$. teinuria levels than HIV patients $(7.9 \pm 3.9$ vs $5 \pm 5.5 \mathrm{~g} / 24 \mathrm{~h}$ ) and lower Scr values (although, not statistically significant). Histological data revealed a trend for a lesser degree of interstitial infiltrate, interstitial fibrosis and tubular atrophy, classified overall as moderate to severe. Microcysts were only found in two patients, one with acute HBV infection and the other with acute pulmonary tuberculosis. Tubular atrophy correlated with dialysis requirement $(\mathrm{P}<0.05)$. Immunofluorescence was positive in four patients: one staining for $\mathrm{C} 3$ and $\operatorname{IgM}$ and in three patients $\mathrm{C} 3$ and $\operatorname{Ig} \mathrm{A}$ deposits were identified. The patients with $\operatorname{IgA}$ deposition found in renal biopsy presented with chronic HBV infection, use of illegal oral drugs and acute pneumonia.

Follow-up was known in $50 \%$ of these patients. Patient number 7 was on dialysis at the time of diagnosis, started prednisolone $1 \mathrm{mg} / \mathrm{kg}$ during 8 weeks, and as no improvement was noted, steroids were stopped and he continued on dialysis. Patient number 6, a young female, with a preserved renal function (Scr $1 \mathrm{mg} / \mathrm{dL}$ ), started steroids (methylprednisolone $1 \mathrm{~g}$ /day, during 3 days, subsequently prednisolone $20 \mathrm{mg}$ /day for 2 months tapered and stopped) and oral cyclophosphamide $(1.5 \mathrm{mg} / \mathrm{kg} /$ day $)$, which was maintained for 18 months. A reduction of proteinuria (11.4 g $>3 \mathrm{~g})$ was attained and renal function (Scr $1.5 \mathrm{mg} / \mathrm{dL}$ ) was relatively maintained. However, this patient abandoned her appointments and therapy, appearing 14 months afterwards with a marked deterioration of renal function and proteinuria (Scr $4.2 \mathrm{mg} / \mathrm{dL}$ and proteinuria $6 \mathrm{~g} /$ day). No therapy was then tried and she started dialysis 4 months later. Patient number 8 , another female, has been under treatment in the last 2 years. She started prednisolone $(1 \mathrm{mg} / \mathrm{kg}$ /day during 2 months, then tapered up to $20 \mathrm{mg} /$ day) plus cyclosporine $(2 \mathrm{mg} / \mathrm{kg} /$ day, in order to maintain cyclosporine level of $90-100 \mathrm{ng} / \mathrm{mL}$ ) during 15 months. There was a marked reduction of proteinuria $(10.8 \mathrm{~g}>3 \mathrm{~g})$, but Scr increased $(4 \mathrm{mg} / \mathrm{dL}>4.2 \mathrm{mg} / \mathrm{dL})$. 
Table 3. Patients' outcome

\begin{tabular}{|c|c|c|c|c|c|c|c|c|c|c|c|}
\hline Patient & Age & Gender & $\begin{array}{l}\text { HIV/ } \\
\text { Non-HIV }\end{array}$ & Other diseases & Treatment & $\begin{array}{l}\text { Scr } \\
(\mathrm{mg} / \mathrm{dL})^{\mathrm{a}}>\mathrm{b}\end{array}$ & $\begin{array}{l}\text { Prot } \\
(\mathrm{g} / 24 \mathrm{~h})^{\mathrm{a}>\mathrm{b}}\end{array}$ & $\mathrm{RRT}^{\mathrm{a}>\mathrm{b}}$ & Death & Follow-up & Comments \\
\hline 1 & 28 & Male & HIV & $\begin{array}{l}\text { Chronic HCV } \\
\text { infection }\end{array}$ & HAART & $8.6>9$ & $20>$ na & Yes $>$ Yes & Yes & 10 months & $\begin{array}{l}\text { Never stopped } \\
\text { dialysis and died }\end{array}$ \\
\hline 2 & 25 & Male & HIV & None & HAART & $7.5>8$ & $22>$ na & Yes $>$ Yes & Yes & 10 months & $\begin{array}{l}\text { Never stopped } \\
\text { dialysis and died }\end{array}$ \\
\hline 3 & 44 & Male & HIV & None & HAART & $2>1.3$ & $1.8>0.6$ & $\mathrm{No}>\mathrm{No}$ & No & 9 months & $\begin{array}{l}\text { Lost follow-up } \\
\text { in } 2008\end{array}$ \\
\hline 4 & 36 & Male & HIV & $\begin{array}{l}\text { Mycobacterium } \\
\text { infection, } \\
\text { Kaposi } \\
\text { sarcoma }\end{array}$ & HAART & $2.8>4.7$ & $5>3$ & $\mathrm{No}>\mathrm{No}$ & Yes & 8 months & Died \\
\hline 5 & 28 & Female & HIV & $\begin{array}{l}\text { Chronic HBV } \\
\text { infection }\end{array}$ & HAART & $2.8>1.9$ & $3>1$ & $\mathrm{No}>\mathrm{No}$ & No & 10 months & Is under treatment \\
\hline 6 & 20 & Female & Non-HIV & $\begin{array}{l}\text { CMV infection } \\
\text { Ascaris } \\
\text { infection }\end{array}$ & $\mathrm{PDN}+\mathrm{CFF}$ & $1>8$ & $11.4>3$ & No $>$ Yes & No & $\begin{array}{l}32 \text { months; } \\
36 \text { months }\end{array}$ & $\begin{array}{l}\text { Started dialysis } \\
\text { after } 32 \text { months of } \\
\text { treatment. She is } \\
\text { still on dialysis. }\end{array}$ \\
\hline 7 & 26 & Male & Non-HIV & Drug abuser & PDN & $8>8$ & $7>$ na & Yes $>$ Yes & No & 24 months & $\begin{array}{l}\text { Never stopped } \\
\text { dialysis }\end{array}$ \\
\hline 8 & 46 & Female & Non-HIV & Pneumonia & $\begin{array}{l}\mathrm{PDN}+ \\
\mathrm{CYA}>\mathrm{MMF}\end{array}$ & $4>2.1$ & $10.8>1.9$ & No $>$ No & No & 24 months & Is under treatment \\
\hline 9 & 19 & Female & Non-HIV & None & None & $2.3>2.3$ & $4>4$ & $\mathrm{No}>\mathrm{No}$ & No & 1 month & $\begin{array}{l}\text { Is going to } \\
\text { start treatment }\end{array}$ \\
\hline
\end{tabular}

na - not available.

${ }^{\mathrm{a}}$ When biopsy was performed.

${ }^{\mathrm{b}}$ At the end of follow-up/renal survival.

After a new biopsy which showed an increase in interstitial fibrosis, she started mycophenolate mofetil, and after 6 months, Scr significantly improved (Scr $2.1 \mathrm{mg} / \mathrm{dL}$ ). Patient number 9 will be started shortly on prednisolone and mycophenolate mofetil.

\section{Discussion}

In 1975 the term 'malignant focal segmental glomerulosclerosis' was used to describe a rapidly progressive nephrotic syndrome $[3,14]$, and the first case report of CG was published in 1979. In 1984 the term HIVAN was used to describe CG associated to HIV infection [13], which is frequently seen in Afro-American patients [15-18]. Since

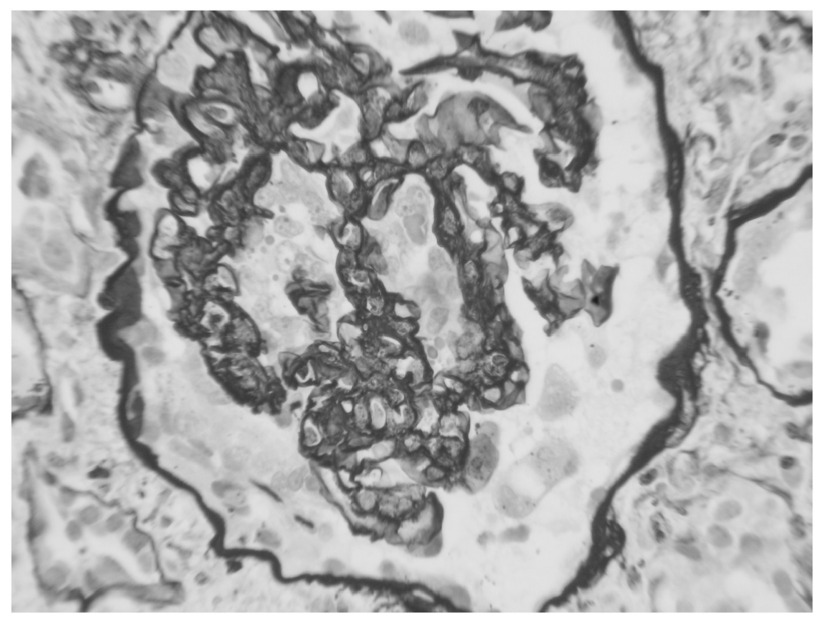

Fig. 3. Collapsing capillaries with hyperplastic podocytes and protein resorption droplets (Jones methenamine silver $\times 400$ ).
1986, the term CG was introduced to define a similar lesion in non-HIV-infected patients $[7,14]$. Although CG is considered to be a variant of FSGS, Barisoni et al. proposed that it should be considered a distinct disorder [19]. In accordance, both FSGS and CG should be considered podocytopathies, as injury to podocytes is the main cause for the disease. FSGS is defined by the presence of focal and segmental injury to glomeruli, foot process effacement and podocytopenia. In comparison, CG is characterized by hyperplastic and hypertrophic podocytes, with collapse and sclerosis of the entire glomerular tuft, along with podocyte proliferation.

It is noteworthy to point out that the origin of the highly proliferating cells around the glomeruli is still a controversy. Recent studies have shown that parietal epithelial cells

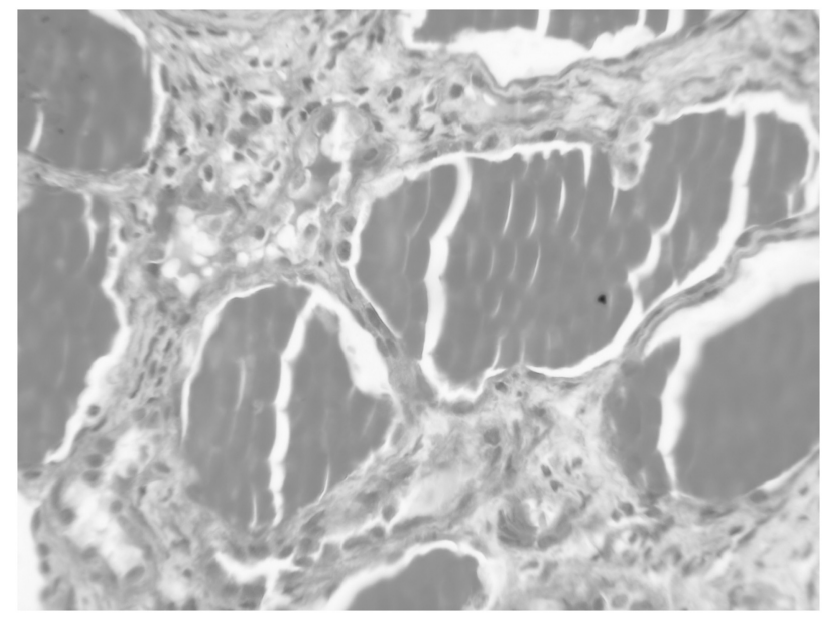

Fig. 4. Microcystic dilatation of the tubules that are filled with proteinaceous casts (Masson trichrome stain $\times 400$ ). 
(PEC) have the capacity to migrate and to differentiate into podocytes, providing a continuous source of podocytes [20]. Bariety et al. showed that parietal podocytes do exist along normal human Bowman's capsule and that these cells express not only the epitopes of mature visceral podocytes but also proproliferative epitopes, maintaining the ability to divide [21]. This is highly complex, as PEC and podocytes have an identical embryonic origin, and proliferating cells may lack specific differentiation markers and probably acquire a different phenotype. Assessment of the CD133 ${ }^{+}$ $\mathrm{CD} 24^{+}$markers in adult human kidney identified a population of renal progenitors, exhibiting self-renewal potential, which are selectively localized at the urinary pole of Bowman's capsule [22]. Accordingly, $\mathrm{CD} 133^{+} \mathrm{CD} 24^{+}$progenitors, or renopoietic system, might be responsible for tubular epithelium and/or podocyte regeneration after injury. Furthermore, a recent study from Smeets and co-workers [23], based on human biopsies, showed that the renopoietic system is responsible for exuberant repair of glomerular injury resulting in CG. Interestingly, embryonic hyperplasia of the Bowman's capsule epithelium, which is the capacity of cells from Bowman's capsule acquires a primitive phenotype, has been described many years ago [24]. In spite of these facts, we believe that CG should be considered a new podocytopathy, until further data are obtained.

In agreement with Barisoni et al., CG is associated with a variety of disorders, which can be grouped in three areas: idiopathic, genetic and secondary or reactive; the latter ones are associated with virus, autoimmune disorders, malignancy, thrombotic microangiopathy, post-transplantation and drugs $[3,14,19]$.

Our study is the second which aims to review data on HIV and non-HIV-related CG. The first study published in 1999 evaluated biopsies from 1979 to 1997, obtaining 60 CG, 42 non-HIV patients and 18 HIV patients [6]. Our first case of CG was in 1994; since then, we received 18 kidney biopsies with collapsing features, 10 HIV-related and 8 non-HIVrelated CG. These data suggest that CG is a very rare condition in the Portuguese population (18/6130), even rarer than in Macedonia residents, in which 16 biopsies were found among 893 native renal biopsies [2]. It may be argued that this number might be higher as only one collapsed glomerulus is required for the diagnosis and this can be easily missed if the biopsy sample consists of only one small core cortex. However, there are some clues, such as severe tubulointerstitial disease and microcystic dilatation of tubules that can imply the diagnosis. Of note, the number of FSGS in our hospital remained similar during this time, presenting a variable incidence range of 7 to $15.4 \%$ yearly.

In our study, patients were mainly black males at the third decade of age. Laurinavicius et al. [6] found a female predominance, although age and race were similar to our data. No differences in terms of gender, dialysis requirement and degree of glomeruli injury between HIV and non-HIV patients were found, similar to Laurinavicius' data.

HIVAN was the most common cause for CG, accounting for $55.6 \%$ of cases. However, Laurinavicius et al. have demonstrated that the majority of CG cases were in non-HIVinfected patients, and in this group, only a minority (13/42) was associated with autoimmune, lymphoproliferative and viral disorders.
Our data showed that in non-HIV-related CG, Caucasian race was predominant and the majority of cases (6/8) were associated with a documented infection, namely acute HBV infection, active pulmonary tuberculosis, acute CMV and $A$. lombricoides infection and acute community pneumonia. Indeed, several infectious diseases, other than HIV, are associated with CG: CMV, HTLV-1, HCV, parvovirus B19, Mycobacterium tuberculosis, Loa loa filariasis and visceral leishmaniasis. Thus, it might be possible that $\mathrm{HBV}$ infection may also be related to this injury. One case of non-HIVrelated CG was associated with illegal use of oral drugs, namely amphetamines and cocaine. Interferon-alpha, valproic acid and pamidronate are some known causative agents of CG. As far as we know, no similar cases relating to amphetamines or cocaine with CG have been reported, although recently collapsing lesions have been related with anabolic steroids abuse [25].

Our HIV-infected patients had a higher percentage of microcystic dilatation of renal tubules, a higher level of tubular atrophy and more severe renal dysfunction than non-HIVinfected patients (Scr $5 \pm 2.3 \mathrm{mg} / \mathrm{dL}$ vs $4.2 \pm 2.7 \mathrm{mg} / \mathrm{dL}$ ). Besides glomerular lesions, HIVAN also develops proliferative tubular lesions. Recently, a group of investigators tried to address the importance of epithelial mesenchymal transition (EMT) in HIVAN phenotype using Tg26 mice [26], since EMT has been reported to contribute to the progression of renal fibrosis in other glomerular and tubulointerstitial lesions [27]. Based on epithelial/mesenchymal markers, this study showed the presence of a significant number of myofibroblasts in periglomerular and peritubular lesions, leading to the conclusion that renal cells EMT plays a role in the development of the proliferative phenotype in HIVAN. This issue needs further confirmation.

It is interesting to highlight that immunofluorescence of non-HIV-related CG revealed the presence of IgA deposits in $37.5 \%(3 / 8)$ of biopsies. The role of it is unclear: a pattern of de novo CG, a pattern of IgA nephropathy or CG coexisting with IgA nephropathy. In fact, IgA nephropathy may be associated with hepatic and/or pulmonary diseases, which were identified in two patients with $\operatorname{Ig} \mathrm{A}$ deposition. It is noteworthy to point that coexistence of CG and membranous glomerulonephritis has been recently identified [28].

The pathogenesis of CG remains unclear. In our population, an association between $C G$ and infections is demonstrated. It has been proved that HIV1 gene products can directly cause collapse of the capillaries [18,29-31]. This raises the hypothesis that infected cellular elements and/or host derived co-factors may be involved in the pathogenesis of infection-associated CG. In addition, immunoglobulin may induce CG [14]. Interestingly, rats subjected to immunoglobulin, obtained from patients with CG, may also develop the disease [32]. This could be the underlying mechanism for development of CG in autoimmune and malignancy disorders, viral infection and post-transplantation. The role of genetic traits, such as the association between $\mathrm{CG}$ and $\mathrm{MHC}$ genes, $\mathrm{CG}$ and genes encoding mitochondrial function or genes linked to action myoclonus-renal syndrome and mandibuloacral dysplasia have also been found [14]. Albaqumi et al. [3] propose a speculative 'best-fit model' for CG based in models of response to death in epi- 
thelial cells. In this 'best-fit model', necrotic or apoptotic epithelium due to an intrinsic or extrinsic insult, communicates with adjacent cells, promoting their hyperplasia. This aberrant proliferation culminates in capillary collapse and microcystic formation. It also may be possible that a number of different insults may be necessary to induce podocyte deregulation on a genetic sensible cell.

There is no established treatment for non-HIV-related $\mathrm{CG}$ in comparison to treatment of HIVAN where HAART seems to be effective. The therapeutic approach to nonHIV-related CG is not easy, as the nature of the disease is not yet totally understood and is not treated in separate clinical trials. We feel that steroids alone are insufficient for the treatment of this aggressive disease, and a combination of immunosuppressive drugs, consistent with Appel's recommendations [33], may be the best approach, except for patients already on dialysis, in which benefits of the therapy are reduced. Length of treatment is, similarly, not certain. Data from Laurinavicius' study showed that of the 42 non-HIV patients treated with a combination of steroids, cyclosporin A or other cytostatic therapy, the majority progressed to end-stage renal failure and $17 \%$ died within 14 months of follow-up [6]. Mycophenolate mofetil is an interesting drug due to its relative renal specificity and lower incidence of side effects. It might be that in future monoclonal antibodies, in particular rituximab, may be used for CG. At least two reports has described successful data $[34,35]$. Also, it is probable that CG associated to secondary causes, in particular infections or cancer, may remit with treatment of the underlying disease [36], which is well known for other glomerular diseases such as membranous glomerulonephritis associated with cancer.

HAART has been demonstrated to be effective for treatment of HIVAN [37-42], suggesting that HIV patients will have a better outcome, as no definitive treatment exists for non-HIV patients. Nevertheless, CYC202, a cyclindependent kinase inhibitor has promised good results for treatment of CG in mice [5].

Unfortunately, the major limitation of this study is the missing data on follow-up in half of the patients. Half of the biopsies came from outside of our hospital. In addition, some patients have abandoned nephrology and infectiology appointments, which obviously cause missing prospective data. Nevertheless, it seems that, in HIVAN, early treatment with HAART appears to be effective for preserving renal function and reducing proteinuria. For non-HIV patients, immunosuppressive therapy with cyclosporine and/or mycophenolate mofetil seemed to allow the preservation of renal function and the reduction of proteinuria when started before initiating dialysis.

\section{Conclusion}

$\mathrm{CG}$ is a very rare condition in the Portuguese population, it is mainly associated with infections, namely HIV, HBV, CMV and pulmonary tuberculosis, affecting predominantly male and black patients at the third decade of life. No cases associated with malignancy or autoimmune diseases were found. CG in HIV patients displayed a higher percentage of microcystic dilatation of renal tubules. More studies are needed to clarify the aetiology, the pathogenesis and the treatment of CG.

Conflict of interest statement. The results in this paper have not been published previously in whole or part, except in abstract form, in the World Congress of Nephrology and ERA EDTA Congress Milan, May 2009.

\section{References}

1. Schwimmer JA, Markowitz GS, Valeri A et al. Collapsing glomerulopathy. Semin Nephrol 2003; 23: 209-218

2. Grcevska L, Polenakovik M. Collapsing glomerulopathy: clinical characteristics and follow up. Am J Kidney Dis 1999; 33: 652-657

3. Albaqumi M, Soos TJ, Barisoni L et al. Collapsing glomerulopathy. $J$ Am Soc Nephrol 2006; 17: 2854-2863

4. Meyrier AY. Collapsing glomerulopathy: expanding interest in a shrinking tuft. Am J Kidney Dis 1999; 33: 801-803

5. Gherardi D, D'Agati V, Chu TH et al. Reversal of collapsing glomerulopathy in mice with the cyclin-dependent kinase inhibitor CYC202. J Am Soc Nephrol 2004; 15: 1212-1222

6. Laurinavicius A, Hurwitz S, Rennke HG. Collapsing glomerulopathy in HIV and non HIV patients: a clinicopathological and follow up study. Kidney Int 1999; 56: 2203-2213

7. Weiss MA, Daquioag E, Margolin EG et al. Nephrotic syndrome, progressive irreversible renal failure, and glomerular "collapse": a new clinicopathological entity? Am J Kidney Dis 1986; 7: 20-28

8. Moudgil A, Nast CC, Bagga A et al. Association of parvovirus B19 infection with idiopathic collapsing glomerulopathy. Kidney Int 2001; 59: 2126-2133

9. Tomlinson L, Boriskin Y, McPhee I et al. Acute cytomegalovirus infection complicated by collapsing glomerulopathy. Nephrol Dial Transplant 2003; 18: 187-189

10. Markowitz GS, Appel GB, Fine PL et al. Collapsing focal segmental glomerulosclerosis following treatment with high-dose pamidronate. J Am Soc Nephrol 2001; 12: 1164-1172

11. Markowitz GS, Fine PL, D'Agati VD. Nephrotic syndrome after treatment with pamidronate. Am J Kidney Dis 2002; 39: 1118-1122

12. Barri YM, Munshi NC, Sukumalchantra S et al. Podocyte injury associated glomerulopathies induced by pamidronate. Kidney Int 2004; 65: 634-641

13. Pardo V, Aldana M, Colton RM et al. Glomerular lesions in the acquired immunodeficiency syndrome. Ann Intern Med 1984; 101: 429-434

14. Albaqumi M, Barisoni L. Current views on collapsing glomerulopathy. J Am Soc Nephrol 2008; 19: 1276-1281

15. Shah SN, He CJ, Klotman P. Update on HIV-associated nephropathy. Curr Opin Nephrol Hypertens 2006; 15: 450-455

16. Ross MJ, Klotman PE. Recent progress in HIV associated nephropathy. J Am Soc Nephrol 2002; 13: 2997-3004

17. Szczech LA, Gupta SK, Habash R et al. The clinical epidemiology and course of the spectrum of renal diseases associated with HIV infection. Kidney Int 2004; 66: 1145-1152

18. Weiner NJ, Goodman JW, Kimmel PL. The HIV associated renal diseases: current insight into pathogenesis and treatment. Kidney Int 2003; 63: 1618-1631

19. Barisoni L, Schnaper W, Kopp J. A proposed taxonomy for the podocytopathies: a reassessment of the primary nephrotic diseases. Clin $J$ Am Nephrol 2007; 2: 529-542

20. Appel D, Kershaw D, Smeets B et al. Recruitment of podocytes from glomerular parietal epithelial cells. J Am Soc Nephrol 2009; 20: 333-343

21. Bariety J, Mandet C, Hill GS et al. Parietal podocytes in normal human glomeruli. J Am Soc Nephrol 2006; 17: 2770-2780

22. Romagnani P. Toward the identification of a "Renopoietic System"? Stem Cells 2009; 27: 2247-2253 
23. Smeets B, Angelotti ML, Rizzo P et al. Renal progenitor cells contribute to hyperplastic lesions of podocytopathies and crescentic glomerulonephritis. J Am Soc Nephrol 2009; 20: 2593-2603

24. Hughson MD, McManus JF, Hennigar GR. Studies on 'end-stage' kidneys. II. Embryonal hyperplasia of Bowman's capsular epithelium. Am J Pathol 1978; 91: 71-84

25. Herlitz LC, Markowitz GS, Farris AB et al. Development of focal segmental glomerulosclerosis after anabolic steroid abuse. J Am Soc Nephrol 2010; 21: 163-172

26. Yadav A, Vallabu S, Kumar D et al. HIVAN phenotype: consequence of epithelial mesenchymal transdifferentiation. Am J Physiol Renal Physiol 2010; 298: F734-F744

27. Zeisberg M, Duffield JS. Resolved: EMT produces fibroblasts in the kidney. J Am Soc Nephrol 2010; 21: 1247-1253

28. Al-Shamari A, Yeung K, Levin A et al. Collapsing glomerulopathy coexisting with membranous glomerulonephritis in native kidney biopsies: a report of 3 HIV-negative patients. Am J Kidney Dis 2003; 42: 591-595

29. Bruggeman LA, Ross MD, Tanji N et al. Renal epithelium is a previously unrecognized site of HIV-1 infection. J Am Soc Nephrol 2000; 11: 2079-2087

30. Husain M, Gusella GL, Klotman ME et al. HIV-1 Nef induces proliferation and anchorage-independent growth in podocytes. J Am Soc Nephrol 2002; 13: 1806-1815

31. Winston JA, Bruggeman LA, Ross MD et al. Nephropathy and establishment of a renal reservoir of HIV type 1 during primary infection. $N$ Engl J Med 2001; 344: 1979-1984

32. Avila-Casado Mdel C, Perez-Torres I, Auron A et al. Proteinuria in rats induced by serum from patients with collapsing glomerulopathy. Kidney Int 2004; 66: 133-143

33. Appel GB. Personal communication in 32nd Annual Medicine Course - Renal Biopsy in Medical Diseases of the Kidneys. New York: Columbia University, August 2009
34. Bitzan M, Ouahed JD, Krishnamoorthy $\mathrm{P}$ et al. Rituximab treatment of collapsing C1q glomerulopathy: clinical and histopathological evolution. Pediatr Nephrol 2008; 23: 355-361 Epub 2008 Mar 20

35. Kaito H, Kamei K, Kikuchi E et al. Successful treatment of collapsing focal segmental glomerulosclerosis with a combination of rituximab, steroids and ciclosporin. Pediatr Nephrol 2010; 25: 957-959 Epub 2009 Dec 22

36. Rodrigues CE, Sette LH, Torritani J et al. Tuberculosis-associated collapsing glomerulopathy: remission after treatment. Ren Fail 2010; 32: 143-146

37. Schwartz EJ, Szczech LA, Ross MJ et al. Highly active antiretroviral therapy and the epidemic of HIV+ end stage renal disease. J Am Soc Nephrol 2005; 16: 2412-2420

38. Wali RK, Drachenberg CI, Papadimitriou JC et al. HIV-1-associated nephropathy and response to highly active antiretroviral therapy. Lancet 1998; 352: 783-784

39. Kirchner JT. Resolution of renal failure after initiation of HAART: 3 cases and a discussion of the literature. AIDS Read 2002; 12: 103105, 110-112

40. Chemlal K, Nochy D, Kenouch S et al. Dramatic improvement of renal dysfunction in a human immunodeficiency virus-infected woman treated with highly active antiretroviral therapy. Clin Infect Dis 2000; 31: 805-806

41. Betjes MG, Verhagen DW. Stable improvement of renal function after initiation of highly active anti-retroviral therapy in patients with HIV-1-associated nephropathy. Nephrol Dial Transplant 2002; 17 : 1836-1839

42. Ferreira AC, Carvalho D, Carvalho Fet al. Collapsing glomerulopathy a treatable disease? Port J Nephrol Hypert 2008; 22: 255-258

Received for publication: 27.4.10; Accepted in revised form: 15.10.10

\title{
Tip variant of focal segmental glomerulosclerosis: outcome and comparison to 'not otherwise specified' variant
}

\author{
Luis F. Arias, Catalina Franco-Alzate and Shirley L. Rojas
}

PRYT Group, Department of Pathology, Faculty of Medicine, University of Antioquia, Medellín, Colombia

Correspondence and offprint requests to: Luis F. Arias; E-mail: 1farias@kidneypathology.com

\begin{abstract}
Background. The clinical significance of focal segmental glomerulosclerosis (FSGS) tip variant remains unclear. With the aim to determine its clinical and histological features, and natural history, we studied our cases of patients with this glomerular lesion.

Methods. This is a retrospective analysis. All native renal biopsies from patients diagnosed as FSGS, between 1998 and 2006, were revised for cases with tip variant. Glomer-
\end{abstract}

ulosclerosis (GS), segmental lesions and interstitial fibrosis (IF) were quantified. We analysed clinical and followup data and compared with cases of FSGS not otherwise specified (NOS).

Results. In 248 primary FSGS cases, 37 corresponded to tip variant $(14.9 \%)$. Median age was 17 years (range $1-$ $65) ; 13(35.1 \%)$ patients were $<15$ years old, and $56.8 \%$ were males. All patients had nephrotic proteinuria. At diagnosis, there were no significant differences for age, 